4. Nguyễn Mạnh Linh. Đánh giá kết quả phẫu thuât thay khớp háng bán phần không xi măng điều trị gãy liên mấu chuyên xương đùi ở bệnh nhân trến 80 tuổi. Luận Văn Thạc Sỹ Học. 2020;Đai hoc Y Hà Nôi.

5. Abdel MP, Watts CD, Houdek MT, Lewallen DG, Berry DJ. Epidemiology of periprosthetic fracture of the femur in 32644 primary total hip arthroplasties: a 40-year experience. Bone Jt J. 2016;98-B(4):461-467. 620X.98B4.37201

6. Ngô Văn Toàn, Trân Trung Dũng, Nguyễn Hữu Nam. Điều trị gãy liên mấu chuyển xương đùi bằng nẹp DHS tại bệnh viện Việt Đức. Tạp Chí Nghiên Cứu Học. 2013;84 (4):69-75.
7. Nguyễn Huy Thành. Đánh giá kết quả điều trị gãy liên mấu chuyển xương đùi bằng kết hợp xương nẹp khóa tại Bệnh viện Hữu nghị Việt Đức. Đại Học Hà Nội. 2018; Luận văn thạc sĩ Y học.

8. Sinno $K$, Sakr $\mathbf{M}$, Girard J, Khatib H. The effectiveness of primary bipolar arthroplasty in treatment of unstable intertrochanteric fractures in elderly patients. North Am J Med Sci. 2010;2(12):561-568. doi:10.4297/najms.2010.2561

9. Tu D, Liu $\mathbf{Z}$, Yu $\mathbf{Y}$. Internal Fixation versus Hemiarthroplasty in the Treatment of Unstable Intertrochanteric Fractures in the Elderly: A Systematic Review and Meta-Analysis. Orthop Surg. 2020;12(4):1053-1064. doi:10.1111/os.12736

\title{
HÌNH THÁI ỐNG TỦY RĂNG SỐ 7 HÀM DƯớI TRÊN PHIM CBCT
}

\section{Đỗ Thị Thu Hương*, Đinh Diệu Hồng*, Phạm Thị Thu Hiền*, Nguyễn Anh Chi*, Phạm Như Hải*}

\section{TÓM TẮT}

Chụp cắt lớp vi tính chùm tia hình nón (CBCT) là phương pháp hố trợ đắc lực cho điều trị nội nha. Mục đích của nghiên cứu này là xác định hình thái của ống tủy răng hàm 7 hàm dưới. CBCT của 346 bệnh nhân đã được sử dụng. Kết quả như sau: Số lượng chân răng theo thứ tự: 3 chân răng $(1,7 \%), 2$ chân răng $(97,8 \%), 1$ chân răng $(0,5 \%)$. Sự khác nhau bên phải và trái không có ý nghĩa thống kê. $47,7 \%$ răng chân gân chỉ có 1 ống tủy, nữ $(56,4 \%)$ cao hơn nam $(36,1 \%) .96,4 \%$ răng chân xa có 1 ống tủy. Hình thái ống tủy chữ $\mathrm{C}$ chiếm $21,7 \%$, trong đó hinh thái $\mathrm{C} 1$ chiếm $14,2 \%$ và $C 2$ chiếm $5,5 \%$. Sự khác nhau bên phải và trái không có ý nghĩa thống kê, nhưng hay gặp ở nữ $(24,9 \%)$ hơn là ở nam $(17,5 \%)$.

Tư khóa: ống tủy, nội nha, cone-beam, răng 7 hàm dưới.

\section{SUMMARY \\ ROOT CANAL MORPHOLOGY OF} MANDIBULAR SECOND MOLARS ON CBCT

Cone-beam computed tomographic (CBCT) imaging is a useful method for endodontic therapy. The aim of this study was to identify morphology of second lower molar root canal . CBCT of 346 patients were used. Results were as follows: Number of roots is $3(1,7 \%), 2(97,8 \%), 1(0,5 \%)$. No difference on the right and left side. $47,7 \%$ of the mesio-bucal root teeth have only 1 root canal, women $(56,4 \%)$ higher than men $(36,1 \%)$, the difference . $96,4 \%$ distal roots have only one canal. The morphology of the C-shaped canal accounts for $21,7 \%$, of which the $\mathrm{C} 1$ form accounts for $14,2 \%$ and C2 accounts for $5,5 \%$. No

*Trường Đại học Y Dược-Đại học Quốc Gia Hà Nội Chịu trách nhiệm chính: Đinh Diệu Hồng Email: dieuhong201@gmail.com

Ngày nhận bài: 8.4.2021

Ngày phản biên khoa học: 25.5 .2021

Ngày duyệt bài: 9.6.2021 difference between right and left, but more common in women $(24,9 \%)$ than in men $(17,5 \%)$.

Key words: root canal, endodontic, cone-beam computed tomographic,

\section{I. ĐẶT VẤN ĐỀ}

Hình thái học tủy răng là một vấn đề rất phức tạp liên quan chặt chẽ đến chuyên ngành điều trị nội nha, đặc biệt là với nhóm răng hàm lớn việc điều trị tủy răng gặp nhiêu khó khăn hơn nhóm răng trước. Việc nhận biết được các biến thể trong hình thái ống tưy rất quan trọng để điêu trị nội nha thành công, cho phép bác sĩ tiên lượng điều trị tránh thất bại, đặc biệt trong quá trình sưa soạn và hàn kín ống tủy. Do mổi răng đều có đặc điểm riêng, do đó mỗi nhóm răng sẽ có một số lượng lớn các biến thể về số lượng và hình thái ống tủy. Những đặc điểm như vậy làm khó khăn trong việc tạo hình, làm sạch và trám bít hệ thống ống tủy ba theo 3 chiêu không gian.

Rắng hàm lớn hàm dưới thứ hai thường được mô tả trong tài liệu là có 2 chân răng và 3 ông tủy mà chưa nêu ra được các biến thể cũng như tỷ lệ các biến thể đó để giúp các bác sĩ lâm sàng lựa chọn công cụ và phương pháp sửa soạn và hàn kín hệ thống ống tủy một cách phù hợp.

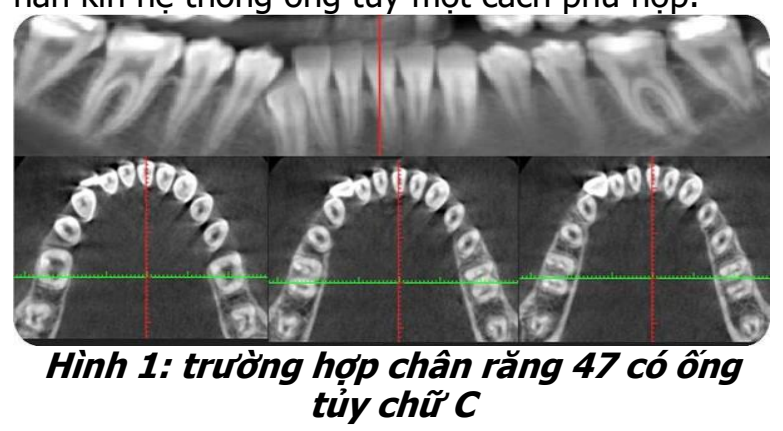


Hiện nay, những tiến bộ công nghệ trong chụp phim răng trên lâm sàng, nhất là phim CTCB đã cho phép thu được hình ảnh chân răng theo 3 chiều không gian, cho phép mô tả chính xác về hình thái răng; tái tạo hình ảnh hệ thống ống tủy và các chi tiết giải phẫu liên quan. Mỗi chủng tộc lại có cấu tạo giải phẫu răng khác nhau, thậm chí đặc điểm vùng miền cũng có thể góp phần tạo sự khác biệt về hình thái và giải phẫu[1,2]. Do đó với mục đích đưa thêm thông tin giúp các bác sĩ răng hàm mặt có những dữ liệu tham khảo về hệ thống ống tủy răng 7 hàm dưới ở người miền bắc chúng tôi đã tiến hành nghiên cứu này với mục tiêu:

1. Xác định số lượng và hinh thái ống tủy của răng 7 hàm dưới bằng phim Conebeam ở người khu vực Hà Nôi và lân cận.

2. Tim mối tương quan giữa giới tính và hình thái ống tủy răng 7 hàm dưới

\section{II. Đốl TƯỢNG VÀ PHƯƠNG PHÁP NGHIÊN CỨU}

2.1 Đối tượng: Mẫu nghiên cứu gồm 346 răng hàm lớn thứ hai hàm dưới phải và trái trên 346 phim conebeam CT của bệnh nhân Hà Nội và vùng lân cận, gồm 151 nam và 195 nữ, tuổi từ 18 đến 55 tuổi, độ tuổi trung bình là 26,8 28,2 .

\section{Tiêu chuẩn chọn mẫu:}

1. Có đủ 2 răng số 7 hàm dưới

2. Các răng số 7 hàm dưới có chân răng phát triển hoàn toàn

3. Hình ảnh conebeam $\mathrm{CT}$ rõ ràng, thể hiện được hình ảnh các ống tủy.

Tiêu chuẩn loại trừ: Các răng số 7 hàm dưới đã bị

1. Tiêu ngót chân răng

2. Trám bít hoặc có miếng trám đến tủy

3. Phục hồi kim loại như chốt, mão

4. Nghiêng hoặc mọc ngâm

\section{Cỡ mẫu}

$$
\mathrm{n}=\frac{\mathrm{Z}^{2} 1-\alpha / 2 \mathrm{P}(1-\mathrm{P})}{\mathrm{d}^{2}}
$$

Răng cối lớn thứ hai hàm dưới: dựa vào kết quả nghiên cứu của Ajinkya Mansing Pawar (2017), tỉ lệ răng cối lớn thứ hai hàm dưới có 2 ống tủy là $79,35 \%$ [6]. Áp dụng vào công tức tính cõ̃ mẫu:

Độ tin cậy 95\%, Z (1- a/2) =1,96; d=0,05 Cõ mẫu tối thiểu là 252 răng.

2.2 Phương pháp nghiên cứu: Nghiên cứu thực hiện theo thiết kế cắt ngang mô tả phân tích trên conebeam CT. Bệnh nhân đã được chụp conebeam CT bằng máy Galileos (Sirona Dental System Inc., Đức), kích cõ voxel $0,3 \mathrm{~mm} x$ $0,3 \mathrm{~mm} \times 0,3 \mathrm{~mm}$, Gray scale 12 bit tại bộ môn
Răng Hàm Mặt, Đại học Y dược, Đại Học Quốc Gia Hà Nội và phòng chụp Xquang Hà Thành trong khoảng thời gian từ tháng 6 năm 2019 đến tháng 4 năm 2021.

Quan sát hình ảnh bằng phần mềm Galileos Viewer (Sirona Dental System Inc.) trên màn hình 24 inch có độ phân giải $1.920 \times 1.200$, độ tương phản $1.000: 1$, bề dày mỗi lát cắt $1 \mathrm{~mm}$. Trình tự thực hiện như sau:

Đầu tiên, điều chỉnh lát cắt trên cửa sổ Tangential đi qua đúng giữa trục chân răng của từng chân răng hàm lớn II cần đo. Sau đây, điêu chỉnh mặt phẳng cắt trên cửa sổ Cross-sectional theo đúng trục của răng hàm được đo. Di chuyển lát cắt trên cửa sổ Axial để kiểm tra số lượng và hình thái ống tủy của mỗi chân răng (hình 2).

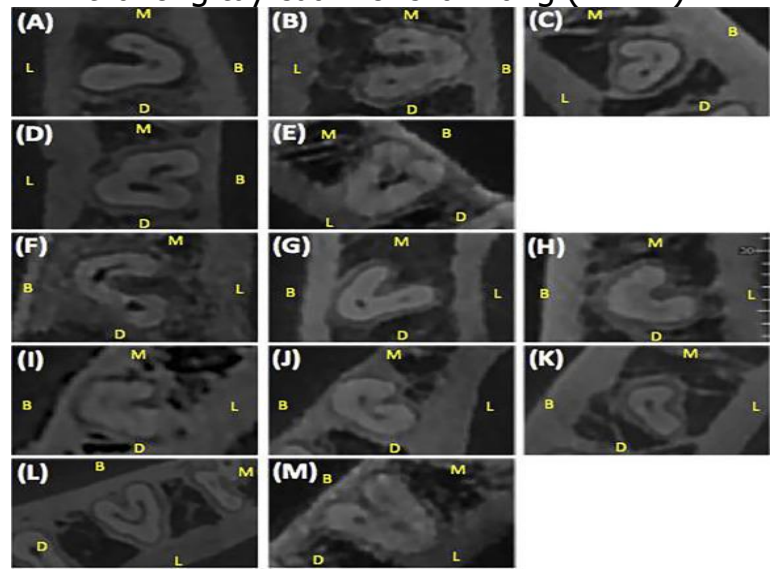

Hinh 2: Phim CT conebeam, điều chinh để quan sát hinh thái ống tủy răng hàm lớn thứ hai hàm

dưới, bên trái (hình phóng to các lát cắt).

Điều tra viên chính khảo sát hình ảnh conebeam CT của từng bệnh nhân để chọn bệnh nhân và chọn răng thỏa mãn tiêu chuẩn chọn mẫu. Bệnh nhân và răng được chọn được ghi nhận dữ liệu chung và dữ liệu về hình thái chân răng và ống tủy. Quan sát từng răng, từng chân răng, đo ở 2 thời điểm khác nhau, nếu số liệu khác nhau thì sẽ nhờ người thứ 2 kiểm tra.

Hình thái ống tủy: được ghi nhận theo phân loại Vertucci (1984)[2,3]. Những ống tủy có hình thái khác ngoài phân loại Vertucci được ghi nhận theo số ống tủy thay đổi theo chiều dài chân răng từ cổ đến chóp.

Hình thái ống tủy: ghi nhận theo phân loại Vertucci (1984) gồm 8 loại (hình 3):

Loại I: chỉ có một ống tủy từ buồng tủy đến lỗ chóp chân răng.

Loại II: có hai ống tủy xuất phát từ buồng tủy tạo thành hai ống tủy riêng biệt nhưng gặp nhau ở gần chóp để thành một ống tủy và ra khỏi chân răng bằng một lỗ chóp. 


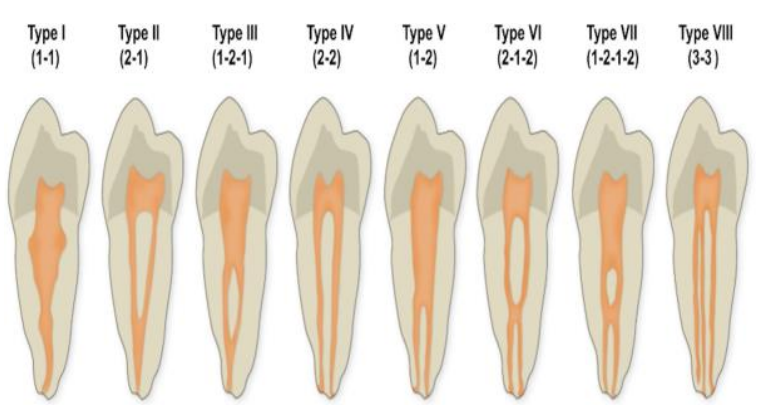

Hình 3: Phân loại hình thái ống tủy theo Vertucci

Loại III: có một ống tủy xuất phát từ buồng tủy nhưng sau đó chia hai và gặp nhau ở gần chóp để tạo một ống tủy và ra khỏi chân răng bằng một î̃̂ chóp.

Loại IV: có hai ống tủy riêng biệt kéo dài từ buồng tủy tới chóp chân răng.

Loại V: một ống tủy xuất phát từ buồng tủy, sau đó tách ra thành hai ống tủy và đi khỏi chân răng bằng hai lỗ chóp riêng biệt.

Loại VI: hai ống tủy xuất phát từ buồng tủy, kết hợp lại thành một ống tủy và sau đó lại chia hai ở chóp với hai lỗ chóp riêng biệt.

Loại VII: một ống tủy xuất phát từ buồng tủy, chia hai sau đó kết hợp lại thành một ống tủy và lại chia hai ở chóp với hai lỗ chóp riêng biệt.

III. KẾT QUẢ NGHIÊN CứU

3.1. Xác định số lượng và hình thái ống tủy của răng 7 hàm dưới bằng phim Conebeam ở người khu vực Hà Nô̂i và lân cân.

3.1.1. Số lượng chẩn răng 7 hàm dưới

Bảng 1: Số lượng chân răng 7 hàm dưới

\begin{tabular}{|c|c|c|c|c|c|}
\hline Số lượng chân & Răng 37 & Răng 47 & $\mathbf{P}$ & Tống & Tỷ lệ \\
\hline 1 chân & 1 & 2 & 1 & 3 & $0,5 \%$ \\
\hline 2 chân & 337 & 340 & 0,602 & 677 & $97,8 \%$ \\
\hline 3 chân & 8 & 4 & 0,382 & 12 & $1,7 \%$ \\
\hline 4 chân & 0 & 0 & & 0 & 0 \\
\hline Tống & $\mathbf{3 4 6}$ & $\mathbf{3 4 6}$ & & $\mathbf{6 9 2}$ & \\
\hline
\end{tabular}

Số lượng chân răng 2 bên phải và trái khác biệt nhau không có ý nghĩa thống kê. Chủ yếu là 2 chân răng chiếm $97,8 \%$, sau đấy là răng 3 chân $(1,7 \%)$, răng 1 chân $(0,5 \%)$ rất ít gặp.

3.1.2. Hình thái ống tủy chân gần của răng 7 hàm dưới theo Vertucci

Bảng 2: Hình thái ống tủy chân gần của răng 7 hàm dưới theo Vertucci

\begin{tabular}{|c|c|c|c|c|c|}
\hline Hình thái ống tủy & Răng 37 & Răng 47 & $\mathbf{P}$ & Tống & Tỷ lệ \\
\hline Loại I theo Vertucci & 165 & 164 & 1 & 329 & $47,7 \%$ \\
\hline Loại II theo Vertucci & 82 & 79 & 0,857 & 161 & $23,3 \%$ \\
\hline Loại III theo Vertucci & 14 & 18 & 0,587 & 32 & $4,6 \%$ \\
\hline Loại IV theo Vertucci & 74 & 78 & 0,783 & 152 & $21,9 \%$ \\
\hline Loại V theo Vertucci & 10 & 5 & 0,296 & 15 & $2,1 \%$ \\
\hline Loại VI theo Vertucci & 1 & 2 & 1 & 3 & $0,4 \%$ \\
\hline Loại VII theo Vertucci & 0 & 0 & & 0 & 0 \\
\hline Loại VIII theo Vertucci & 0 & 0 & & 0 & 0 \\
\hline Tống & $\mathbf{3 4 6}$ & $\mathbf{3 4 6}$ & & $\mathbf{6 9 2}$ & \\
\hline
\end{tabular}

Chân gần ngoài răng 7 dưới chủ yếu có 1 ống tủy thắng từ trên xuống (vertucci I) chiếm 47,7\%, tiếp theo đó là chân gần có 2 miệng ống tủy tách ra sau đó hợp lại ở 1/3 chóp (vertucci loại II) chiếm
Ống tủy đến chóp chân răng. nhau tạo thành 1 ống tủy dạng dải cong, hình chữ $\mathrm{C}$. Ống tủy hình $\mathrm{C}$ được quan sát trong thiết diện cắt ngang để ghi nhận hình thái và số lượng ông tủy ở từng phần ba chân răng: phần ba cố, ba giữa và phần ba chóp. Ông tủy hình $\mathrm{C}$ [1](hình 4).

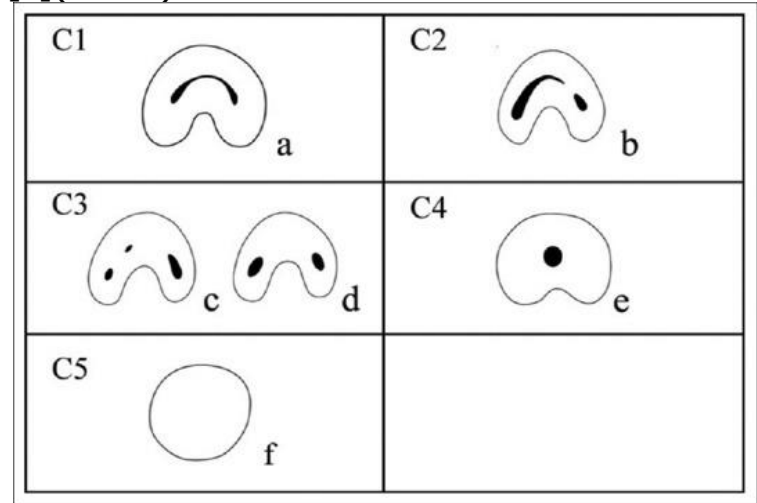

Hình 4: phân loại theo Fan đọc trên phim

Phương pháp xử lý số liệu: xử lý số liệu bằng phần mềm thống kê R4.1.0. 
$23,3 \%$ và chân gần có 2 ống tủy tách rời nhau toàn bộ (vertucci loại IV) chiếm $21,9 \%$. Sự khác nhau bên phải và trái không có ý nghĩa thống kê.

3.1.3. Hình thái ống tủy chân xa của răng 7 hàm dưới theo Vertucci

Bảng 3: Hình thái ống tủy chân xa của răng 7 hàm dưới theo Vertucci

\begin{tabular}{|c|c|c|c|c|c|}
\hline Hình thái ống tủy & Răng 37 & Răng 47 & $\mathbf{P}$ & Tống & Tỷ lệ \\
\hline Loại I theo Vertucci & 332 & 335 & 0,689 & 667 & $96,4 \%$ \\
\hline Loại II theo Vertucci & 3 & 2 & 1 & 5 & $0,7 \%$ \\
\hline Loại III theo Vertucci & 2 & 2 & 1 & 4 & $0,6 \%$ \\
\hline Loại IV theo Vertucci & 1 & 0 & 1 & 1 & $0,1 \%$ \\
\hline Loại V theo Vertucci & 8 & 7 & 1 & 15 & $2,2 \%$ \\
\hline Loại VI theo Vertucci & 0 & 0 & & 0 & 0 \\
\hline Loại VII theo Vertucci & 0 & 0 & & 0 & 0 \\
\hline Loại VIII theo Vertucci & 0 & 0 & & 0 & 0 \\
\hline Tống & $\mathbf{3 4 6}$ & $\mathbf{3 4 6}$ & & $\mathbf{6 9 2}$ & \\
\hline
\end{tabular}

Chân xa chủ yếu chỉ có 1 ống tủy từ lỗ vào ống tủy đến chóp răng (loại I Vertucci) chiếm $96,4 \%$. Sự khác nhau bên phải và trái không có ý nghĩa thống kê.

3.1.4. Hình thái ống tủy hình chữ $C$ răng 7 dưới

Bảng 3: Hình thái ống tửy hình chữ C răng 7 dưới

\begin{tabular}{|c|c|c|c|c|c|}
\hline Hình thái & Răng 37 & Răng 47 & $\mathbf{P}$ & Tống & Tỷ lệ \\
\hline C1 & 60 & 38 & 0,069 & 98 & $14,2 \%$ \\
\hline C2 & 17 & 21 & 0,183 & 38 & $5,5 \%$ \\
\hline C4 4 & 5 & 4 & 1 & 9 & $1,3 \%$ \\
\hline C5 & 1 & 4 & 0,247 & 5 & $0,7 \%$ \\
\hline Tống & 0 & 0 & 0 & 0 & $0,0 \%$ \\
\hline
\end{tabular}

Trong số 692 răng 7 hàm dưới 2 bên thì có 83 răng 37 và 67 răng 47 có hình thái ống tủy chữ $C$ chiếm $21,7 \%$, trong đó hình thái $C 1(14,2 \%)$ và $C 2(5,5 \%)$ chiếm tỷ lệ cao nhất. Sự khác biệt hai bên phải và trái khônng có ý nghĩa thống kê.

3.2. Mối liên quan giới tính với hình thái chân răng 7 hàm dưới

3.2.1. Số lượng chân răng 7 hàm dưới

Bảng 4. Môii liến quan giữa giới tính với số lượng chân răng

\begin{tabular}{|c|c|c|c|c|c|}
\hline Số lượng chân răng & Nam & Tỷ lệ & Nữ & Tỷ lệ & P \\
\hline 1 chân & 0 & 0 & 3 & $0,8 \%$ & 0,345 \\
\hline 2 chân & 293 & $97 \%$ & 384 & $98,4 \%$ & 0,304 \\
\hline 3 chân & 9 & $3,0 \%$ & 3 & $0,8 \%$ & 0,055 \\
\hline chân & 0 & 0 & 0 & 0 & 0 \\
\hline Tống & $\mathbf{3 0 2}$ & & $\mathbf{3 9 0}$ & & \\
\hline
\end{tabular}

Số lượng răng 7 dưới có 2 chân ở nữ $(98,4 \%)$ nhiều hơn nam $(97,0 \%)$ nhưng số lượng răng 7 hàm dưới có 3 chân ở nam $(3,0 \%)$ lại nhiều hơn ở nữ $(0,8 \%)$, khác biệt giữa 2 giới không có ý nghĩa thống kê.

3.2.2. Hình thái chân răng gân theo Vertucci và giới tính

Bảng 5: Môí liên quan giữa giới tính với hinh thái chân gân răng 7 dưới

\begin{tabular}{|c|c|c|c|c|c|}
\hline Hình thái chân răng & Nam & Tỷ lệ & Nũ̃ & Tý lệ & P \\
\hline Loại I theo Vertucci & 109 & $36,1 \%$ & 220 & $56,4 \%$ & $1,686.10^{-7}$ \\
\hline Loại II theo Vertucci & 86 & $28,5 \%$ & 75 & $19,2 \%$ & 0,006 \\
\hline Loại III theo Vertucci & 18 & $6,0 \%$ & 14 & $3,6 \%$ & 0,197 \\
\hline Loại IV theo Vertucci & 80 & $26,5 \%$ & 72 & $18,5 \%$ & 0,015 \\
\hline Loại V theo Vertucci & 8 & $2,6 \%$ & 7 & $1,8 \%$ & 0,616 \\
\hline Loại VI theo Vertucci & 1 & $0,3 \%$ & 2 & $0,5 \%$ & 1 \\
\hline Loại VII theo Vertucci & 0 & $0.0 \%$ & 0 & $0.0 \%$ & \\
\hline Loại VIII theo Vertucci & 0 & $0.0 \%$ & 0 & $0.0 \%$ & \\
\hline Tống & $\mathbf{3 2 0}$ & $\mathbf{4 0 0}$ & & \\
\hline
\end{tabular}

Hình thái chân gần theo Vertucci I ở nữ là $56,4 \%$ cao hơn ở nam $(36,1 \%)$ có ý nghĩa thống kê. Hình thái chân gần theo Vertucci II ở nam là $28,5 \%$ cao hơn ở nữ $(19,2 \%)$ có ý nghĩa thống kê. Hình thái chân gần theo Vertucci IV ở nam là $26,5 \%$ cao hơn ở nữ $(18,5 \%)$ có ý nghĩa thống kê. Các hình 
thái khác sự khác biệt giữa nam và nữ không có ý nghĩa thống kê.

3.2.3. Hình thái chân răng xa theo Vertucci và giới tính

Bảng 6: Mối liên quan giữa giới tính với hinh thái chân xa răng 7 dưới

\begin{tabular}{|c|c|c|c|c|c|}
\hline Hình thái chân răng & Nam & Tỷ lệ & Nữ & Tỷ lệ & P \\
\hline Loại I theo Vertucci & 288 & $95,4 \%$ & 376 & $97,2 \%$ & 0,297 \\
\hline Loại II theo Vertucci & 1 & $0,3 \%$ & 4 & $1,0 \%$ & 0,532 \\
\hline Loại III theo Vertucci & 3 & $1,0 \%$ & 1 & $0,3 \%$ & 0,4504 \\
\hline Loại IV theo Vertucci & 1 & $0,3 \%$ & 0 & 0 & 0,901 \\
\hline Loại V theo Vertucci & 9 & $3,0 \%$ & 6 & $1,5 \%$ & 0,311 \\
\hline Loại VI theo Vertucci & 0 & $0.0 \%$ & 0 & $0.0 \%$ & \\
\hline Loại VII theo Vertucci & 0 & $0.0 \%$ & 0 & $0.0 \%$ & \\
\hline Loại VIII theo Vertucci & 0 & $0.0 \%$ & 0 & $0.0 \%$ & \\
\hline Tống & $\mathbf{3 0 2}$ & & $\mathbf{3 8 7}$ & & \\
\hline
\end{tabular}

Hình thái chân xa theo Vertucci chủ yếu là loại I ở nữ là 97,2\% cao hơn ở nam $(95,4 \%)$ khác biệt không có ý nghĩa thống kê. Hình thái chân xa theo Vertucci các loại khác là ít gặp.

3.2.4. Hình thái ống tủy hình chũ $C$ răng 7 dưới

Bảng 6: Mối liên quan giứa giới tính với hinh thái ống tủy chữ C

\begin{tabular}{|c|c|c|c|c|c|}
\hline Hình thái & Nam & Tỷ lệ & Nữ & Tỷ lệ́ & P \\
\hline C1 & 33 & $62,3 \%$ & 65 & $67 \%$ & 0,686 \\
\hline C2 3 & 16 & $30,2 \%$ & 22 & $22,7 \%$ & 0,146 \\
\hline C4 & 4 & $7,5 \%$ & 5 & $5,15 \%$ & 0,818 \\
\hline C5 & 0 & 0 & 5 & $5,15 \%$ & 0,228 \\
\hline Tống số răng có hình chữ C & 0 & $0.0 \%$ & 0 & $0.0 \%$ & \\
\hline Tống số răng theo giới & 53 & $17,5 \%$ & 97 & $24,9 \%$ & 0,026 \\
\hline
\end{tabular}

Hình thái ống tủy C hay gặp ở nữ (24,9\%) hơn nam (17,5\%) khác biệt có ý nghĩa thống kê

\section{BÀN LUẬN}

Trong số 692 răng 7 hàm dưới nghiên cứu thì chúng tôi nhận thây chủ yếu là 2 chân răng chiếm $97,8 \%$, sau đấy là răng 3 chân $(1,7 \%)$, và 1 chân $(0,5 \%)$ rất ít gặp. Số lượng chân răng 2 bên phải và trái khác biệt nhau không có ý nghĩa thống kê. So với nghiển cứu của Huỳnh Hữu Thục Hiền năm 2019 [4] trên 936 răng 7 hàm dưới ở người miền nam thì $98,1 \%$ có 2 chân, $1,8 \%$ có 3 chân, $0,8 \%$ có 1 chân. Như vậy số răng 7 hàm dưới có 2 chân của chúng tôi khá tương đồng của Huỳnh Hữu Thục Hiền và Elham M.Senan [5], nhưng lớn hơn so với nghiên cứu của Ajinkya Mansing Pawar [6] và Sezer Demirbuga [9] (Bảng 7) ở các chủng tộc khác [8] (dao động từ $79,35 \%$ đến $90 \%$ ),

Bảng 7: So sánh số lượng chân răng

\begin{tabular}{|c|c|c|c|c|c|}
\hline Tác giả & Đối tượng & Cỡ mâu & 1 chân & 2 chân & 3 chân \\
\hline Elham M. Senan, 2020 & CBCT & 448 & $0,8 \%$ & $98,6 \%$ & $0,6 \%$ \\
\hline Ajinkya Mansing Pawar, 2017 & CTCB & 983 & $13,12 \%$ & $79,35 \%$ & $7,53 \%$ \\
\hline Sezer Demirbuga, 2013 & CBCT & 925 & $11,15 \%$ & $85,4 \%$ & $3,45 \%$ \\
\hline Bilge Gulsum Nur, 2014 & CBCT & 1165 & $9,99 \%$ & $90 \%$ & $0,01 \%$ \\
\hline
\end{tabular}

Về hình thái ống tủy chân răng nghiên cứu của chúng tôi thì các chân răng xa chủ yếu thuộc dạng có 1 ống tủy giống với kết quả của nhiều nghiên cứu khác, chân gần thì ngoài 1 ống tủy chiếm ưu thế $(47,7 \%)$ thì có các biến thể khác Vertucci 2-6, nhiều hơn nếu so với nghiên cứu của nhiêu tác giả khác $[5,6,8]$ (Bảng 8). Điều này có thể do đặc điểm giải phẫu của người Việt Nam.

Bảng 8: Hình thái ống tủy chân gần răng 7 dưới theo Vertucci

\begin{tabular}{|c|c|c|c|c|c|c|c|c|c|c|}
\hline Tác Giả & Đối tượng & Cỡ mâu & I & II & III & IV & V & VI & VII & VIII \\
\hline Huỳnh Hữu Thục Hiền, 2020 & CTCB & 936 & $29,6 \%$ & $32,9 \%$ & $8,5 \%$ & $22,9 \%$ & $5 \%$ & - & - & - \\
\hline Elham M. Senan, 2020 & CTCB & 448 & $4 \%$ & $56,9 \%$ & $15,6 \%$ & $18,8 \%$ & $1,1 \%$ & $1,1 \%$ & - & - \\
\hline Ajinkya Mansing Pawar, 2017 & CTCB & 983 & $7,23 \%$ & $23,55 \%$ & $0,91 \%$ & $45,7 \%$ & $1,02 \%$ & - & - & - \\
\hline Bilge Gulsum Nur, 2014 & CBCT & 1165 & $12,4 \%$ & $2,1 \%$ & $0,7 \%$ & $79,6 \%$ & $5,2 \%$ & - & - & - \\
\hline
\end{tabular}

Hình thái ống tủy chữ $C$ trong nghiên cứu của chúng tôi chiếm $21,7 \%$, lớn hơn nhiều nghiên cứu của Martin J [8] ở người Bồ Đào Nha trên phim conebeam CT chỉ có 93 răng chiếm 8,6\% trong tổng số 1088 răng, với các loại hình thái chữ $C$ theo Bảng 9, trong đấy chiếm nhiêu nhất là loại C3 khác 
với nghiên cứu của chúng tôi là loai $\mathrm{C} 1$.

Bảng 9: So sánh tỷ lê \% ống tủy chữ C ở răng 7 hàm dưới của Martins

\begin{tabular}{|c|c|c|c|c|c|c|}
\hline Của Martins J, 2016 & Loại C1 & Loại C2 & Loại C3 & Loại C4 & Loại C5 & \% ống tủy chứ C \\
\hline Tỷ lệ \% & $21,1 \%$ & $23,4 \%$ & $38,1 \%$ & $17,2 \%$ & 0,25 & $8,6 \%$ \\
\hline Của chúng tồi (Tỷ lệ \%) & $14,2 \%$ & $5,5 \%$ & $1,3 \%$ & $0,7 \%$ & 0 & $21,7 \%$ \\
\hline
\end{tabular}

\section{KẾT LUÂ̂N}

Số lượng chân răng 2 bên phải và trái khác biệt nhau không có ý nghĩa thống kê. Răng 7 dưới thường có 2 chân $(97,8 \%)$, sau đây là 3 chân $(1,7 \%), 1$ chân $(0,5 \%)$.

Chân gần răng 7 hàm dưới chủ yễu có 1 ống tủy thẳng từ trên xuống (vertucci $\mathrm{I}$ ) chiếm $47,7 \%$, nữ $(56,4 \%)$ cao hơn nam $(36,1 \%)$. Sự khác nhau bên phải và trái không có ý nghĩa thống kê. Chân xa chủ yếu chỉ có 1 ống tủy từ lỗ vào ống tủy đến chóp răng (loại I Vertucci)

Hình thái ống tủy chữ $C$ chiếm $21,7 \%$ số răng 7 hàm dưới được nghiên cứu, trong đó hình thái C1 chiếm $14,2 \%$ và $C 2$ chiếm $5,5 \%$. Không khác biệt 2 bên phải trái, nhưng hay gặp ở nữ $(24,9 \%)$ hơn là ở nam $(17,5 \%)$.

\section{LờI CẢM ƠN}

Chúng tôi xin cảm ơn bộ môn Răng Hàm Mặt - Trường Đại Học Y Dược - ĐHQGHN, đã tạo điều kiện cơ sở vật chất và đối tượng nghiên cứu để hoàn thành để tài.

\section{TÀI LIẸU THAM KHẢO}

1. Bing Fan, C-Shaped Canal System in Mandibular Second Molars: Part II-Radiographic Features. Journal of Endodontics, 2005. 32(5): p. 250-254.
2. Bansal, R., S. Hegde, and M.S. Astekar Classification of Root Canal Configurations: A Review and a New Proposal of Nomenclature System for Root Canal Configuration. Journal of Clinical and Diagnostic Research, 2018.

3. VERTUCCI, F.J., Root canal morphology and its relationship to endodontic procedures. Endodontic Topics, 2005. 10, : p. 3-29.

4. Hiền, H.H.T., Đắc Điểm Hình Thái Chân Răng Và Ông Tủy Răng Cổi Lớn Thứ Nhất Và Thứ Hai Người Việt Nam . Luận án Tiến sĩ, trường Đại Học Y Dược TP Hồ Chí Minh, 2019.

5. Ahmed $\mathbf{H}$, Root and canal morphology of permanent mandibular molars in a Sudanese population. International Endodontic Journal. 2007;40:766-71.

6. Pawar A et al. Root canal morphology and variations in mandibular second molar teeth of an Indian population: an in vivo cone-beam computed tomography analysis. Clinical oral investigations. 2017;21:2801-9.

7. Nur BG, Evaluation of the root and canal morphology of mandibular permanent molars in a south-eastern Turkish population using cone-beam computed tomography. European journal of dentistry. 2014; 8:154-9.

8. Martins, J.N, Prevalence and Characteristics of the Maxillary C-shaped Molar. J Endod, 2016. 42(3): 383-9.

9. Sezer Demirbuga, Use of cone-beam computed tomography to evaluate root and canal morphology of mandibular first and second molars in Turkish individuals. Medicina Oral, Patologia Oral y Cirugia Bucal. 2013; 18(4): 737-44.

\section{ĐÁNH GIÁ Độ XOAY TRỤC CỦA THỦY TINH NHÂN TẠO ĐA TIÊU ĐIỀU CHİNH LOẠ THI}

\section{TÓM TẮT}

Mục tiêu: đánh giá độ xoay trục của thể thủy tinh nhân tao (TTTNT) đa tiêu điều chỉnh loạn thi Acrysof ReSTOR Toric (ART) trên bệnh nhân được phẫu thuật phaco đặt TTTNT ART. Đối tượng và phương pháp nghiên cứu: Nghiên cứu can thiệp lâm sàng tiến cứu trên 52 mắt của 46 bệnh nhân đục thể thủy tinh kèm loạn thị giác mạc từ 1,00-3,00D, được phẩu thuật phaco đặt thể thủy tinh nhân tạo đa tiêu điêu chỉnh loạn thị Acrysof ReSTOR Toric. Thời gian theo dõi sau

*Bênh viênn Mắt Trung ương

Chịu trách nhiệm chính: Vũ Tuấn Anh

Email: vta.oph@gmail.com

Ngày nhận bài: 9.4.2021

Ngày phản biên khoa học: 26.5.2021

Ngày duyệt bài: 8.6.2021

\section{Vũ Tuấn Anh*, Trần Thị Hoàng Nga*}

1 tuân, 1 tháng, 3 tháng, 6 tháng, 1 năm bao gồm độ xoay trực IOL, thị lực, độ loạn thị tồn dư. Kết quả: Sau mổ 1 tuần, $15,38 \%$ mắt lêch trục IOL trong đó $75 \%$ dưới 3 độ, $25 \%$ từ 3 độ đến 5 độ, độ xoay trục trung bình $2,42 \pm 1,12^{\circ}$. Sau mổ 1 tháng đển 12 tháng có $17,31 \%$ mắt xoay trục IOL, $100 \%$ dưới 5 độ, độ xoay truc trung bình là $2,28 \pm 1,34^{\circ}$. Khi truc IOL xoay dưới 3 độ, độ loạn thị tồn dư trung bình là $-0,12 \pm 0,08$ $\mathrm{D}$, khi trục IOL xoay trên 3 độ, độ loạn thị tồn dư trung bình là $-0,37 \pm 0,26$. Trục IOL xoay càng nhiều thì độ loạn thị tồn dư càng lớn với $p<0,05$. Những mắt bị lệch trục IOL có thị lực nhìn xa, nhìn gần và nhìn trung gian chưa chỉnh kính sau mổ thấp hơn so với những mắt không bị lệch trục $I O L$ với $p<0,001$. Kết Iuận: Điều chỉnh loạn thị bằng toric IOL đã trở thành một lựa chọn cho nhiều phẫu thuật viên nhãn khoa. Đánh giá độ xoay trục IOL là một bước quan trọng không thể thiếu khi theo dõi bệnh nhân sau phẫu 